\title{
Respiratory virus associated with surgery in children patients
}

\author{
Zhang Dan ${ }^{1,2+}$, Xiuyu Lou ${ }^{2+}$, Hao Yan², Junhang Pan², Haiyan Mao ${ }^{2}$, Hongfeng Tang ${ }^{3}$, Yan Shu ${ }^{3}$, Yun Zhao ${ }^{3}$, \\ Lei Liü, Junping Li ${ }^{3}$, Dong Chen ${ }^{4}$, Yanjun Zhang ${ }^{2 *}$ and Xuejun $\mathrm{Ma}^{1 *}$
}

\begin{abstract}
Background: Viral respiratory infection (VRI) is a common contraindication to elective surgery. Asymptomatic shedding among pediatric surgery patients (PSPs) could potentially lead to progression of symptomatic diseases and cause outbreaks of respiratory diseases. The aim of this study is to investigate the incidence of infection among mild symptomatic PSP group and asymptomatic PSP group after surgical procedure.

Methods: We collected the induced sputum from enrolled 1629 children (under 18 years of age) with no respiratory symptom prior to pediatric surgery between March 2017 and February 2019. We tested 16 different respiratory virus infections in post-surgery mild symptomatic PSP group and asymptomatic PSP group using a quantitative real-time reverse transcriptase polymerase chain reaction (qRT-PCR) assay panel. We analyzed symptom data and quantitative viral load to investigate the association between viruses, symptoms and viral quantity in qRT-PCR-positive PSPs.
\end{abstract}

Results: Out of 1629 children enrolled, a total of 204 respiratory viruses were present in 171 (10.50\%) PSPs including 47 patients with mild symptoms and 124 with no symptoms after surgery. Commonly detected viruses were human rhino/enterovirus (HRV/EV, 42.19\%), parainfluenza virus 3 (PIV3, 24.48\%), coronavirus (CoV NL63, OC43, HKU1, 11.46\%), and respiratory syncytial virus (RSV, 9.9\%). PIV3 infection with a higher viral load was frequently found in PSPS presenting with mild symptoms, progressing to pneumonia with radiographic evidence after surgery. HRV/EV were the most commonly detected pathogens in both asymptomatic and mild symptomatic PSPs. CoV (OC43, HKU1) infections with a higher viral load were mostly observed in asymptomatic PSPs progressing to alveolar or interstitial infiltration.

Conclusions: Our study suggested that PIV3 is a new risk factor for VRI in PSPs. Employing a more comprehensive, sensitive and quantitative method should be considered for preoperative testing of respiratory viruses in order to guide optimal surgical timing.

Keywords: Respiratory virus, Pediatric surgical patients, Symptoms, mRT-PCR

\section{Background}

Respiratory virus is well known to cause significant morbidity and mortality in pediatric populations [1-3]; especially in neonates or very young infants; in patients with chronic heart or lung disease; and in the immunosuppressed [4]. Numerous studies have described viral

\footnotetext{
*Correspondence: yjzhang@cdc.zj.cn; maxj@ivdc.chinacdc.cn

${ }^{2}$ Institute of Microbiology, Zhejiang Provincial Center for Disease Control and Prevention, No. 3399 Binsheng Road, 310051, Binjiang district, Hangzhou, China

${ }^{1}$ NHC Key Laboratory of Medical Virology and Viral Diseases, National Institute for Viral Disease Control and Prevention, Chinese Center for Disease Control and Prevention, No.155 Changbai Road, Changping district, Beijing 102206, China

Full list of author information is available at the end of the article
}

respiratory infection (VRI) as a leading cause of illness and death in people of all ages [5]. The most frequent community-acquired respiratory viruses are respiratory syncytial virus (RSV), parainfluenza virus (PIV), human influenza virus (IV), human metapneumovirus (HMPV), and human rhinovirus (HRV) in the respiratory infection patients, hematopoietic cell transplant recipients, and hematologic malignancy patients with an immunocompromised status [3, 6-9].

Most observations of human respiratory virus carriage are derived from medical surveillance. As VRIs can often be mild or asymptomatic and typically go undocumented, individuals may not seek medical care because either the infection is mild or it elicits symptoms not severe enough 
to warrant contacting a medical professional [10]. Asymptomatic viral shedding in the nasopharynx in asymptomatic populations and immunocompetent hosts is relatively common [11-13]. Asymptomatic shedding among pediatric surgery patients (PSPs) could potentially play an key role in propagating outbreaks of respiratory diseases if subclinical VRI is transmissible and leads to progression of symptomatic disease [13]. However, the infections reported by the surveillance showed only the symptomatic fraction of the total infected population [14]. The role of asymptomatic infection in respiratory virus transmission is still largely unknown and the rates of asymptomatic shedding are not well studied.

The issue of preoperative VRI screening among children undergoing surgery is unclear and complex. If children with VRI presented with obvious symptoms (fever, cough), it would be an easy decision for the surgeon or anesthesiologist to delay surgery if appropriate. In cases of children with mild or no symptoms, it becomes very difficult for doctors to make the right decision. A few studies have investigated VRI associated with a limited number of respiratory viruses and have demonstrated an increased length of stay (LOS) and increased postoperative complication rates in pediatric cardiac surgical patients $[15,16]$. The data for VRI among the PSPs is not performed systematically recorded and thus detailed etiologic data are lacking. To better estimate the current state of VRI in PSPs and to improve clinical management, this study aims to investigate the incidence of VRI in the mild symptomatic and asymptomatic pediatric surgery population after surgical procedures and to evaluate the impact of VRI on postoperative outcomes. We analyzed detailed symptom data using a standardized symptom survey and quantitative viral load using multiple GRT-PCR to determine the associations between viruses, symptoms and viral quantity.

\section{Methods}

\section{Study design and patients}

This was a retrospective surveillance study of pediatric patients after surgery at the Children's Hospital, Zhejiang University School of Medicine, China. Children (age $<18$ year) undergoing a surgical procedure between March 2017 and February 2019 were eligible for enrollment. We obtained induced sputum specimens from hospitalized patients within $48 \mathrm{~h}$ of admission regardless of the presence of respiratory symptoms, as part of standard care in the hospital. If pediatric patients had serious symptoms suggestive of respiratory infections before surgery and must delay surgery, these patients were excluded from analysis. The PSPs who had no respiratory symptom prior to elective or emergency surgery were included in the study. After surgery, study subjects completed a baseline information form and a standardized symptom survey that included six symptoms (fever [17], wheezing, sputum, shortness of breath, soar throat and cough) and radiographic findings (alveolar or interstitial infiltrate and pleural effusion). Fever was defined as a body temperature $\geq 38.0^{\circ} \mathrm{C}$. Mild symptoms refer to the subjects who had at least one of the above respiratory symptoms that were not severe. A clinical chart review was performed for subjects to determine whether symptoms occurred outside of the study visit. Data on management and outcome of the cases were collected from the medical records. The study was approved by the institutional ethics review board at the Center for Disease Control and Prevention of Zhejiang, including a waiver of informed consent.

\section{Virologic methods}

Sputum samples were collected from each patient in the hospital. The samples were subsequently divided into two aliquots and stored at $-80^{\circ} \mathrm{C}$ until required for the assay. Nucleic acids were extracted from $200-\mu \mathrm{L}$ samples using the cador Pathogen 96 QIAcube HT Kit (Qiagen) for automated viral DNA and RNA extraction with the QIAcube HT System. The samples were tested individually by qRT-PCR using specific primers and probes targeting different genomes according to our previously reported qRT-PCR methods [18]. The qRT-PCR assays were used to detect 16 different respiratory viruses: $\mathrm{CoV}$ (229E, NL63, OC43 and HKU1), PIV1-4, IV types A and $\mathrm{B}, \mathrm{RSV}$ types $\mathrm{A}$ and $\mathrm{B}, \mathrm{HRV} / \mathrm{EV}, \mathrm{HMPV}$, human adenovirus (ADV), and human bocavirus ( $\mathrm{HBoV})$.

\section{Comparison of $\mathrm{Ct}$ values}

qRT-PCR threshold cycle $(\mathrm{Ct})$ represents the first PCR cycle in which fluorescent signal for the target (eg: viral RNA) is greater than the minimal detection level. Ct values are inversely related to the viral load, thus offering a semiquantitative assessment. Lower $\mathrm{Ct}$ values were considered to reflect a higher viral load than the higher $\mathrm{Ct}$ values. We compared $\mathrm{Ct}$ values between mild symptomatic and asymptomatic PSPs for different viruses in each positive sample when viruses were detected in PSPs with a prevalence of $>5 \%$. Statistical analyses were performed using Stata 13 software. Differences were considered significant when $p<0.05$ (two-sided).

\section{Statistical methods}

We summarized and compared surgical patients demographic data between respiratory virus-positive and virus-negative groups using chi-square or Fisher's exact test for categorical variables and Wilcoxon rank-sum test for continuous variables, as appropriate. We used Student-Newman-Keuls test to assess whether there were statistical differences in the $\mathrm{Ct}$ values of different respiratory viruses between mild symptomatic and 
asymptomatic PSPs. For categorical variables, such as age group and gender, we used Fisher's exact test, ANOVA and Mann-Whitney $U$ test to compare the differences across each categorical variable with respect to positivity. Each virus detected was counted individually. For example, in the case of co-detection of HRV and PIV3, detection of each virus was considered positive in separate HRV and PIV3 prevalence calculations.

\section{Results}

\section{Respiratory virus incidence}

Of the 4414 eligible children, 1629 patients were enrolled. We surveyed 1629 patients undergoing a surgical procedure during the study period (Fig. 1). Among them, $52.87 \%$ of participants were female and $47.13 \%$ were male. Respiratory samples from 171 (10.50\%) of 1629 subjects had one or more respiratory viruses detected (Table 1), of which, 47 (2.88\%) subject were from mild symptomatic group and 124 (7.62\%) from asymptomatic group (Fig. 1). There was no difference in median age between qRT-PCR-positive and -negative patients. The epidemiology of the respiratory disease varied substantially among the different pediatric age group (Table 1). The median LOS of qRT-PCR-positive and -negative patients in the entire cohort was 18.0 days (IQR, 11.027.0) and 13.0 days (IQR, 9.0-21.0), respectively. Thus, patients with viral respiratory illness were more likely to have a longer postoperative LOS $(p<0.001$, Table 1$)$.

A total of 204 respiratory viruses were detected in 171 PSPs. A single virus was detected in 141 PSPs (8.66\%), and 30 PSPs $(1.84 \%)$ had multiple viruses identified, which was involved with 63 respiratory viruses. The most commonly identified viruses were HRV/EV (81,
42.19\%), followed by PIV3 (47, 24.48\%), RSV (19, 9.90\%), CoV OC43 (13, 6.77\%), IV (10, 5.2\%), HboV (8, 4.17\%), and CoV HKU1 (8, 4.17\%) (Table 2). HRV/EV showed the highest rate of infection among respiratory viruses and accounted for 25(12.25\%) detected co-infections. The most commonly detected co-infections were HRV/ EV and PIV3 (15,7.35\%). CoV 229E and PIV4 were not detected in the PSPs. Figure 2 demonstrates the incidence and type of pathogen according to months of the year. Detection of PIV3 increased during the spring and summer and HRV was detected year-round, whereas other viruses were observed with no clear seasonal distribution.

\section{Symptoms and VRI}

In general, patients reported symptoms more frequently in the survey form when their respiratory samples tested positive than when their samples tested negative. The following viruses were further investigated to explore the association between symptoms and viral infections: $\mathrm{HRV} / \mathrm{EV}(n=81)$, RSV $(n=19)$, PIV3 $(n=47)$, IV $(n=$ $10)$, and $\mathrm{CoV}$ (OC43, HKU1, $n=21)$. These viruses were detected in both asymptomatic patients and patients with mild symptoms (Table 2). Other viruses were not analyzed because of small numbers of positivity. Overall, $\mathrm{CoV}$ and HRV/EV were associated with lower proportion of symptoms and PIV3, IV and RSV were associated with higher proportion of symptoms (Fig. 3). RSVpositive surgical patients had more respiratory symptoms than other viruses had, though RSV was also identified in 3 patients without symptom. The proportion of symptoms presenting in the PSPs were lower in samples that tested positive for PIV3 than for IV, probably

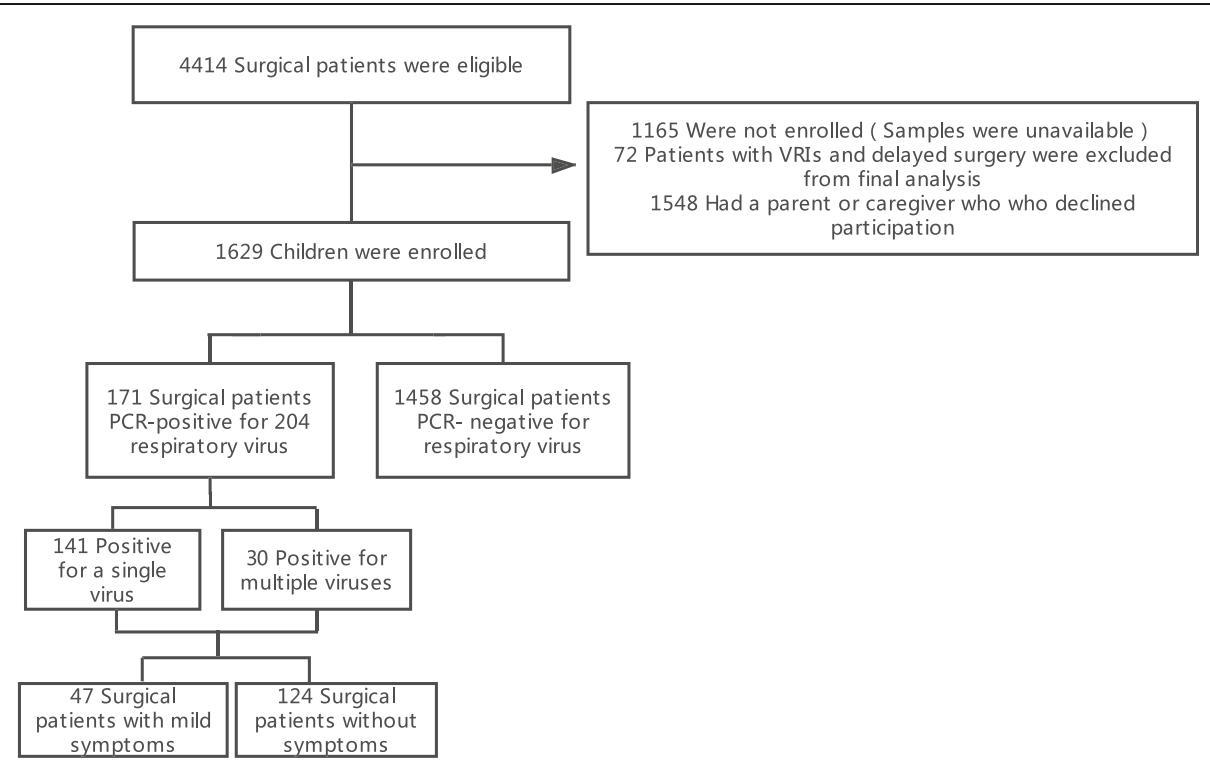

Fig. 1 Consort flow diagram. (Eligibility and Enrollment of Surgery Patients) 
Table 1 Comparison of baseline demographic data and surgical procedural data according to the qRT-PCR results

\begin{tabular}{llll}
\hline Patient demographics & qRT-PCR Positive $(n=171)$ & qRT-PCR Negative $(n=1458)$ & $p$ \\
\hline $\begin{array}{l}\text { Age }(\mathrm{mo}) \text {, median (IQR) } \\
\text { Age category, n. (\%) }\end{array}$ & $8(3.6-22.4)$ & $9.6(3.0-30.6)$ & \\
Neonates age $<29 \mathrm{~d}$ & & $98(6.72)$ & $<0.001$ \\
$29 \mathrm{~d}-3 \mathrm{yr}$ & $(0)$ & $919(63.03)$ \\
$>3 \mathrm{yr}$ & $88(51.46)$ & $441(30.25)$ \\
Male, $\mathrm{n}$ (\%) & $83(48.54)$ & $797(54.67)$ & $13.0(9.0-21.0)$ \\
Length of stay, median (IQR) & $82(48.04)$ & $3(<1)$ & 0.076 \\
Death in the hospital, no. (\%) & $18.0(11.0-21.0)$ & 0.001 \\
\hline
\end{tabular}

$\mathrm{IQR}=$ interquartile range. Continuous variables are represented as median and IQR, and categorical variables are summarized as $n$ (\%)

because of the inclusion of some asymptomatic patients with 29 of PIV3 infection. However, alveolar or interstitial infiltration was most frequently observed in PIV 3positive patients. The proportion of symptoms was lower for $\mathrm{CoV}$ infection than other viruses due to the presence of asymptomatic patients with 11 of $\mathrm{CoV}$ infection. A lower proportion of symptoms but higher rate of radiographic findings (alveolar or interstitial infiltration and pleural effusion) were found in HRV/EV-positive patients, though 70 of HRV/EV infections were identified in asymptomatic patients.

\section{Quantitative respiratory virus load}

To explore a potential association between severity of illness and the virus load, as reflected by the $\mathrm{Ct}$ values, $\mathrm{Ct}$ values were compared among asymptomatic patients and patients with mild symptoms for the viruses detected in PSPs with a prevalence of $>5 \%$. These viruses included $\operatorname{HRV} / \operatorname{EV}(n=81), \operatorname{RSV}(n=19)$,
PIV3 $(n=47)$, IV $(n=10)$, and CoV (OC43, HKU1, $\mathrm{n}=21$ ). Figure 4 showed that median $\mathrm{Ct}$ values for PIV3- and CoV (HKU1, OC43)-positive PSPs were 20.7 and 22.5, respectively, suggesting a significantly higher viral load than that for RSV (26.1), HRV/EV (27.2), or IV (24.2) (ANOVA, $p<0.05$ ). Median Ct values were not significantly different among RVS, HRV/EV and IV (Mann-Whitney $U$ test, $\mathrm{p}<0.05$ ). PIV3 infection with a higher viral load was frequently found in PSPs presenting with mild symptoms, progressing to pneumonia with radiographic evidence after surgery. In the case of CoV (HKU1, OC43)-positive PSPs, the $\mathrm{Ct}$ values were significantly lower than for RSV and IV in patients with severe clinical symptoms supported by radiographic evidence (MannWhitney $U$ test, $p<0.05$, Fig. 4). CoV (OC43, HKU1) infections with a higher viral load were also observed in asymptomatic PSPs progressing to alveolar or interstitial infiltration.

Table 2 Number and percentage of each virus detected among 171 PSPs with mid symptoms and no symptoms

\begin{tabular}{|c|c|c|c|c|c|c|c|c|}
\hline \multirow[t]{2}{*}{ All viruses } & \multicolumn{2}{|c|}{ Positive, no. (\%) } & \multicolumn{2}{|c|}{ Mid Symptoms, no. (\%) } & \multicolumn{2}{|c|}{ Radiographic finding, no. (\%) } & \multicolumn{2}{|c|}{ No Symptoms, no. (\%) } \\
\hline & 204 & $(12.52 \%)$ & 66 & $(4.05 \%)$ & 53 & $(3.25 \%)$ & 137 & $(8.41 \%)$ \\
\hline IV & 10 & $(5.20 \%)$ & 7 & $(3.43 \%)$ & 4 & $(1.96 \%)$ & 3 & $(1.47 \%)$ \\
\hline RSV & 19 & $(9.90 \%)$ & 16 & $(7.84 \%)$ & 6 & (2.94\%) & 3 & $(1.47 \%)$ \\
\hline HRV/EV & 81 & $(42.19 \%)$ & 11 & $(5.39 \%)$ & 14 & (6.86\%) & 70 & $(34.31 \%)$ \\
\hline HMPV & 5 & $(2.60 \%)$ & 4 & $(1.96 \%)$ & 1 & $(0.49 \%)$ & 1 & $(0.49 \%)$ \\
\hline ADV & 7 & (3.65\%) & 4 & $(1.96 \%)$ & 4 & $(1.96 \%)$ & 3 & $(1.47 \%)$ \\
\hline HBoV & 8 & $(4.17 \%)$ & 4 & $(1.96 \%)$ & 3 & $(1.47 \%)$ & 4 & $(1.96 \%)$ \\
\hline PIV1 & 4 & (2.08\%) & - & $N D^{a}$ & - & $N D^{a}$ & 4 & (1.96\%) \\
\hline PIV2 & 1 & $(0.52 \%)$ & - & $N D^{a}$ & - & $N D^{a}$ & 1 & (0.49\%) \\
\hline PIV3 & 47 & (24.48\%) & 18 & (8.82\%) & 16 & (7.84\%) & 29 & (14.22\%) \\
\hline PIV4 & - & $N D^{a}$ & - & $N D^{a}$ & - & $N D^{a}$ & - & $N D^{a}$ \\
\hline Cov OC 43 & 13 & (6.77\%) & 2 & (0.98\%) & 3 & (1.47\%) & 11 & (5.39\%) \\
\hline Cov NL 63 & 1 & $(0.52 \%)$ & - & $N D^{a}$ & - & $N D^{a}$ & - & $N D^{a}$ \\
\hline Cov 229E & - & ND & - & $N D^{a}$ & - & $N D^{a}$ & - & $N D^{a}$ \\
\hline Cov HKU1 & 8 & $(4.17 \%)$ & - & $N D^{a}$ & 2 & (0.98\%) & 8 & (3.92\%) \\
\hline
\end{tabular}

${ }^{\mathrm{a} N D}$, not detected 


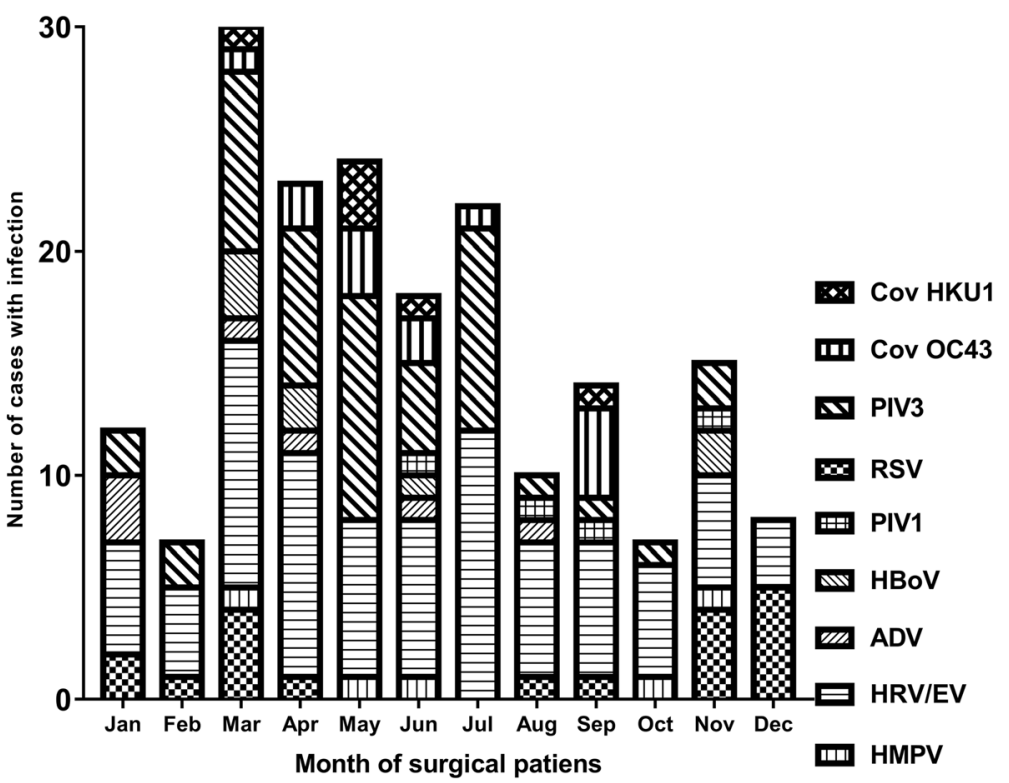

Fig. 2 Histogram showing the frequency and type of pathogen (left axis) according to month, in Zhejiang pediatric patients in the period from March 2017 through February 2019

\section{Discussion}

VIR has the potential to result in serious respiratory disease in postoperative recovery. In previous studies, the significance of VIR in postoperative recovery patients was questioned, as previous studies reported low positive PCR results for common respiratory viruses in 4.2 and $1.7 \%$ of pediatric cardiac surgical patients $[15,16]$. These reported studies were limited to RSV, HRV/EV, and IV, possibly missing the other majority of respiratory viruses. In addition, these studies lacked quantitative analysis of viral pathogens in the PSPs. Though the frequency of symptomatic VRI was low, presence of VRI significantly prolonged postoperative recovery in children following surgery, as evidenced by longer LOS periods in hospitalization. In the present study, we aimed to investigate the infection rates and outcomes of both asymptomatic and symptomatic PSPs leading to VRI after surgery using qRT-PCR. As samples were taken not only from patients with symptoms of infection, but also from asymptomatic patients in this study, we were therefore able to explore the impact of viral testing in asymptomatic patients, which could help improve estimates of VRI in PSPs and further study of disease transmission modeling and forecasting.

A total of 171 out of 1629 children (10.50\%) were confirmed to have VRI with laboratory results, which is

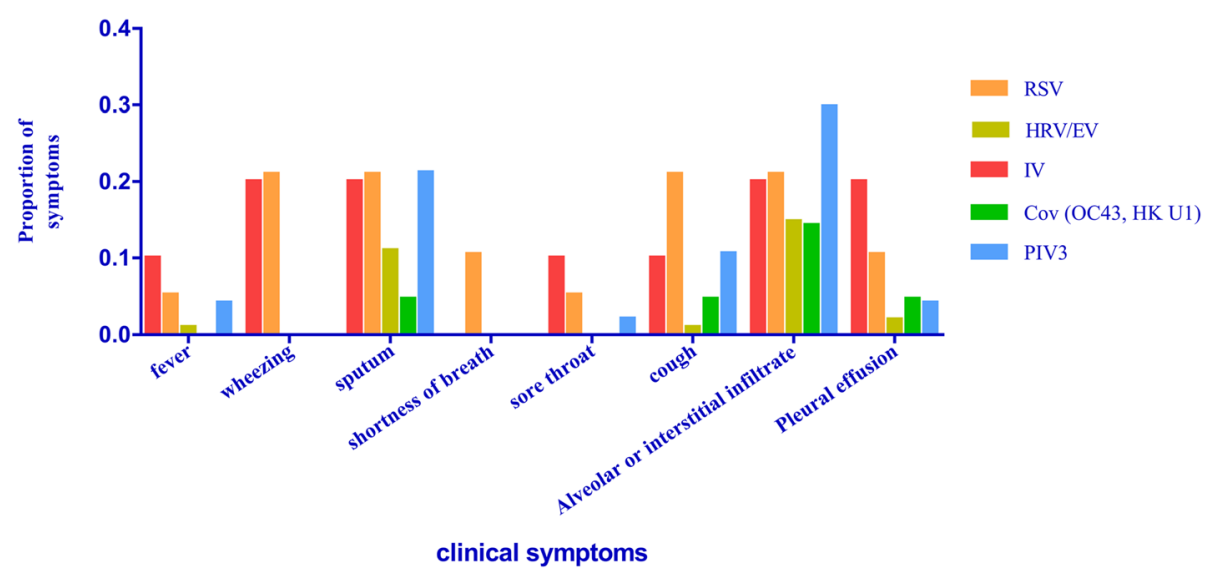

Fig. 3 Symptoms and radiographic findings survey versus respiratory infection data collected from PSPS who were detected positive for respiratory viruses. Proportion of symptoms and radiographic findings reported are shown in respiratory samples that tested positive for HRV/EV, RSV, PIV3, CoV HKU1, CoV OC43 and IV 


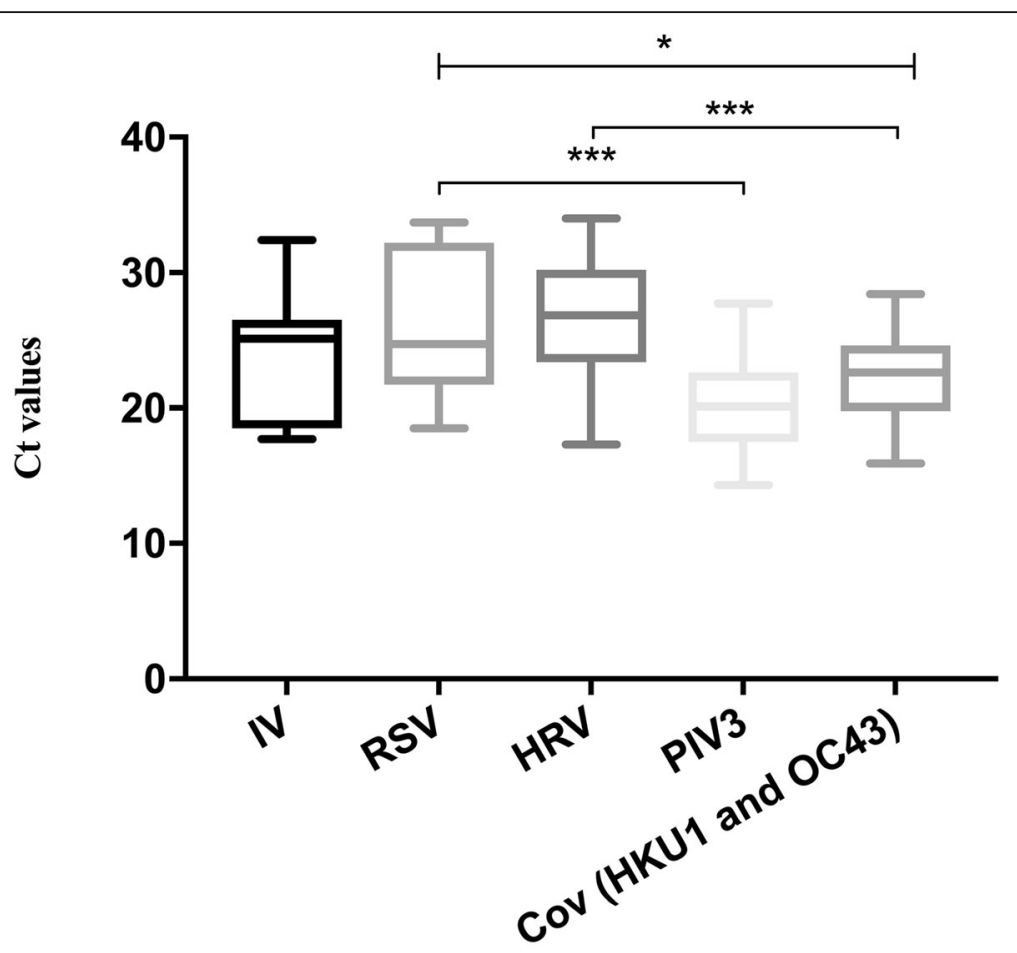

\section{Ct values in pediatric surgery patients}

Fig. 4 Box and whisker plots form qRT-PCR Ct values among PSPs (age < 18 years) positive for RSV, PIV3, HRV/EV, IV and CoV (HKU1 and OC43). The center of each box plot represents the median, with the box denoting the IQR, and the upper and lower whiskers showing the level 1.5 times the IQR above and below the 75th and 25th percentile, respectively. $P$-values were calculated with the Student-Newman-Keuls test. ${ }^{*} p<0.05,{ }^{* *} p<0.01$, ${ }^{* * *} p<0.001$

a considerably higher proportion than previous studies have identified. HRV/EV was the most common pathogen detected in $42.19 \%$ of PSPs, who had either mild symptoms or were asymptomatic, compared to previously reported $17 \%$ of asymptomatic controls and $22 \%$ of children with pneumonia enrolled at the same study sites during the same time period [19]. This might be owing to the high sensitivity of the proposed qRT-PCR assays identifying more viral pathogens. In this study, we also observed that HRV/EV were associated with prolonged shedding and the most commonly found coinfections were PIV3 and HRV/EV. These results are consistent with previous findings that HRV/EV co-infection or different HRV species co-infection were associated with acute respiratory illness hospitalization and that prolonged viral shedding over the course of 30 days was more commonly associated with respiratory viruses [9, 20-23]. Because shedding of HRV can occur more than two weeks after infection [19], it could be interpreted that HRV was the most commonly found co-infection pathogen in this study.

RSV and IV infections with higher Ct values and high proportion of symptoms were detected in 9.90 and $5.20 \%$ of the PSPs, respectively. RSV was the main pathogen detected in children with pneumonia younger than two years of age. RSV and IV caused more severe clinical symptoms, potentially causing patient transfers to the department of respiratory infection or surgery delays in the preoperative period, suggesting lower detection of RSV and IV than other viruses in this study.

In our study, PIV3 infection with a higher viral load was frequently found in PSPs with mild symptoms, and caused pneumonia with radiographic evidence after surgery. These results were consistent with previous reports that PIV3 was frequently detected in patients with bronchiolitis and pneumonia less than one year of age and was the second pathogen to cause VRIs in neonates and young infants. PIV3 infections were most common in the spring and summer in this study, which is similar to previous report [24]. Additionally, PIV3 infections were also found in 29 patients with no symptoms, this result is different from a previous study in which many viruses (ADV, IV, RSV, HMPV, COV and HRV/EV) but no PIV was identified in hospitalized children without symptoms of respiratory viral illness [11]. Our findings suggested that PIV3 is a new risk factor for VRI in PSPs. The PIV3-infected PSPs with mild symptoms or without obviously clinical respiratory symptoms should strictly adhere to the VRI isolation procedures when undergoing elective surgery. In order to prevent and control VRI, further 
study of PIV3 infections in the perioperative period is needed.

In a previous study, CoVOC43 was the most commonly detected coronavirus [25], followed by CoV (NL63 HKU1), with similarly moderate detection frequencies. CoV 229E was detected with a comparatively lower frequency [26, 27]. Similar to previous study, CoV OC43 $(n=13,6.77 \%)$ and CoV HKU1 $(n=8,4.17 \%)$ infections with relatively lower $\mathrm{Ct}$ values and less serious illnesses or radiographic findings, were recognized. However, $\mathrm{CoV}$ (OC43, HKU1) infections with a higher viral load were also observed in asymptomatic PSPs progressing to alveolar or interstitial infiltration. CoV 229E was not discovered in PSPs in this study.

This observational study has several limitations: 1) The small subgroup numbers may lead to differences in detection rates, making it worthwhile to consider a multicenter study with greater numbers of surgical cases to further examine the impact of VRI on postoperative outcomes; 2) The possible bacterial pathogens in the PSP were not considered; 3) no information was available about the vaccination and immunological status of eligible patients.

In conclusion, our findings indicate that VRI is associated with prolonged postoperative recovery in children following surgery. In addition, PIV3 is a new risk factor for VRI in PSPs. Employing a more sensitive and quantitative method, such as qRT-PCR, should be considered for preoperative testing of respiratory viruses. Further prospective studies are required to define the risk stratification and to guide optimal surgical timing.

\footnotetext{
Abbreviations

ADV: Human adenovirus; CDC: Centers for Disease Control and Prevention; CoV: Coronavirus; Ct: Threshold cycle; HBoV: Human bocavirus; HMPV: Human metapneumovirus; HRV: Human rhinovirus; HRV/EV: Human rhino/enterovirus; IQR: Interquartile range; IV: Influenza virus; LOS: Length of stay; PIV3: Parainfluenza virus 3; PSPs: Pediatric surgery patients; qRTPCR: Quantitative real-time reverse transcriptase polymerase chain reaction; RSV: Respiratory syncytial virus; VRI: Viral respiratory infection
}

\section{Publisher's Note}

Springer Nature remains neutral with regard to jurisdictional claims in published maps and institutional affiliations.

\section{Acknowledgements}

We thank all participants at the Children's Hospital, Zhejiang University School of Medicine and the Chinese Center for Disease Control and Prevention of Zhejiang province and the patients for taking part in this study.

\section{Authors' contributions}

DZ, YJZ, and XJM conceived and designed the study. JHP and HYM supervised the day-to-day management at study sites. YZ, LL, HFT, YS, and JPL obtained clinical samples and participated in patient care. CD performed statistical analysis. HY and XYL supervised the confirmatory respiratory viruses RT-PCR. All of the study group members reviewed and contributed to subsequent drafts and approved the final version for manuscript.

\section{Funding}

This work was supported by grants from China Mega-Project for Infectious Disease(2018ZX10711001, 2017ZX10104001 and 2018ZX10713-002), Medical Research Key Project of Hebei Province (20180616), the Key Disciplinary of Health and Family Planning Commission of Zhejiang Province (CX-9), the Monitor Technology Platform of Infectious Diseases of the State Major Science and Technology Special Projects during the 12th five-year plan of China (2017ZX10103008-002), the Health Leading Talents Program of Zhejiang Provincial (2018) 22, Social Development Project of Public Welfare Technology Application of Zhejiang Province(LGF18H190003).

\section{Availability of data and materials}

The datasets used and/or analyzed during the current study are available from the corresponding author on reasonable request.

\section{Ethics approval and consent to participate}

Not applicable.

\section{Competing interests}

The authors have no competing interests to declare.

\section{Author details}

${ }^{1} \mathrm{NHC}$ Key Laboratory of Medical Virology and Viral Diseases, National Institute for Viral Disease Control and Prevention, Chinese Center for Disease Control and Prevention, No.155 Changbai Road, Changping district, Beijing 102206, China. ${ }^{2}$ Institute of Microbiology, Zhejiang Provincial Center for Disease Control and Prevention, No. 3399 Binsheng Road, 310051, Binjiang district, Hangzhou, China. ${ }^{3}$ Department of Pathology, The Children's Hospital, Zhejiang University School of Medicine, Hangzhou, China. ${ }^{4}$ Department of Laboratory Medicine, The Sixth People Hospital of Wenzhou, Wenzhou, China.

Received: 11 March 2019 Accepted: 29 May 2019

Published online: 17 June 2019

\section{References}

1. Walker C, Rudan I, Liu L, Nair H, Theodoratou E, Bhutta Z, O'Brien K, Campbell H, Black R. Global burden of childhood pneumonia and diarrhoea. Lancet. 2013;381:1405-16.

2. Rudan I, O'Brien K, Nair H, Liu L, Theodoratou E, Qazi S, Lukšić I, Fischer Walker C, Black R, Campbell H. Epidemiology and etiology of childhood pneumonia in 2010: estimates of incidence, severe morbidity, mortality, underlying risk factors and causative pathogens for 192 countries. J Glob Health. 2013;3:010401.

3. Shah DP, Shah PK, Azzi JM, Chemaly RF. Parainfluenza virus infections in hematopoietic cell transplant recipients and hematologic malignancy patients: a systematic review. Cancer Lett. 2016:370:358-64.

4. Couch RB, Englund JA, Whimbey E. Respiratory viral infections in immunocompetent and immunocompromised persons. Am J Med. 1997;102:2-9 discussion 25-26.

5. Troeger C, Forouzanfar M, Rao PC, Khalil I, Brown A, Swartz S, Fullman N, Mosser J, Thompson RL, Reiner RC, et al. Estimates of the global, regional, and national morbidity, mortality, and aetiologies of lower respiratory tract infections in 195 countries: a systematic analysis for the global burden of disease study 2015. Lancet Infect Dis. 2017;17:1133-61.

6. Shah DP, Shah PK, Azzi JM, El Chaer F, Chemaly RF. Human metapneumovirus infections in hematopoietic cell transplant recipients and hematologic malignancy patients: a systematic review. Cancer Lett. 2016;379:100-6.

7. Paulsen GC, Danziger-Isakov L. Respiratory viral infections in solid organ and hematopoietic stem cell transplantation. Clin Chest Med. 2017;38:707-26.

8. Seo S, Waghmare A, Scott EM, Xie H, Kuypers JM, Hackman RC, Campbell AP, Choi SM, Leisenring WM, Jerome KR, et al. Human rhinovirus detection in the lower respiratory tract of hematopoietic cell transplant recipients: association with mortality. Haematologica. 2017;102:1120-30.

9. Lehners N, Tabatabai J, Prifert C, Wedde M, Puthenparambil J, Weissbrich B, Biere B, Schweiger B, Egerer G, Schnitzler P. Long-term shedding of influenza virus, parainfluenza virus, respiratory syncytial virus and nosocomial epidemiology in patients with hematological disorders. PLoS One. 2016;11:e0148258. 
10. Birger R, Morita H, Comito D, Filip I, Galanti M, Lane B, Ligon C, Rosenbloom D, Shittu A, Ud-Dean M, et al. Asymptomatic shedding of respiratory virus among an ambulatory population across seasons. mSphere. 2018;3:e0024918.

11. Advani S, Sengupta A, Forman M, Valsamakis A, Milstone AM. Detecting respiratory viruses in asymptomatic children. Pediatr Infect Dis J. 2012:31:1221-6

12. van der Zalm MM, van Ewijk BE, Wilbrink B, Uiterwaal CS, Wolfs TF, van der Ent CK. Respiratory pathogens in children with and without respiratory symptoms. J Pediatr. 2009;154:396-400, 400 e391.

13. Peck AJ, Englund JA, Kuypers J, Guthrie KA, Corey L, Morrow R, Hackman RC, Cent A, Boeckh M. Respiratory virus infection among hematopoietic cell transplant recipients: evidence for asymptomatic parainfluenza virus infection. Blood. 2007;1 10:1681-8.

14. Shaman J, Morita H, Birger R, Boyle M, Comito D, Lane B, Ligon C, Smith H, Desalle R, Planet P. Asymptomatic summertime shedding of respiratory viruses. J Infect Dis. 2018;217:1074-7.

15. Moynihan K, Barlow A, Alphonso N, Anderson B, Johnson J, Nourse C, Schlebusch S, Karl TR, Schlapbach LJ. Impact of viral respiratory pathogens on outcomes after pediatric cardiac surgery. Pediatr Crit Care Med. 2017:18:219-27.

16. Spaeder MC, Carson KA, Vricella LA, Alejo DE, Holmes KW. Impact of the viral respiratory season on postoperative outcomes in children undergoing cardiac surgery. Pediatr Cardiol. 2011;32:801-6.

17. DJ J, RE G, MD E, Z L, PA S, CJ K, E R, KA R, EL A, KT C-D, et al. Rhinovirus illnesses during infancy predict subsequent childhood wheezing. J Allergy Clin Immunol. 2005;116:571-7.

18. Zhang D, Mao H, Lou X, Pan J, Yan H, Tang H, Shu Y, Zhao Y, Cheng X, Tao $\mathrm{H}$, et al. Clinical evaluation of a panel of multiplex quantitative real-time reverse transcription polymerase chain reaction assays for the detection of 16 respiratory viruses associated with community-acquired pneumonia. Arch Virol. 2018;163:2855-60.

19. Jain S, Williams DJ, Arnold SR, Ampofo K, Bramley AM, Reed C, Stockmann C, Anderson EJ, Grijalva CG, Self WH, et al. Community-acquired pneumonia requiring hospitalization among U.S. children. N Engl J Med. 2015;372:835-45.

20. Fry AM, Lu X, Olsen SJ, Chittaganpitch M, Sawatwong P, Chantra S, Baggett $H C$, Erdman D. Human rhinovirus infections in rural Thailand: epidemiological evidence for rhinovirus as both pathogen and bystander. PLoS One. 2011;6:e17780

21. Iwane MK, Prill MM, Lu X, Miller EK, Edwards KM, Hall CB, Griffin MR, Staat MA, Anderson LJ, Williams JV, et al. Human rhinovirus species associated with hospitalizations for acute respiratory illness in young US children. J Infect Dis. 2011;204:1702-10.

22. Jacobs SE, Lamson DM, Soave R, Guzman BH, Shore TB, Ritchie EK, Zappetti D, Satlin MJ, Leonard JP, van Besien K, et al. Clinical and molecular epidemiology of human rhinovirus infections in patients with hematologic malignancy. J Clin Virol. 2015;71:51-8.

23. Zhu Y, Zembower TR, Metzger KE, Lei Z, Green SJ, Qi C. Investigation of respiratory syncytial virus outbreak on an adult stem cell transplant unit by use of whole-genome sequencing. J Clin Microbiol. 2017;55:2956-63.

24. Abedi GR, Prill MM, Langley GE, Wikswo ME, Weinberg GA, Curns AT, Schneider E. Estimates of parainfluenza virus-associated hospitalizations and cost among children aged less than 5 years in the United States, 1998-2010. J Pediatric Infect Dis Soc. 2016;5:7-13.

25. Zeng ZQ, Chen DH, Tan WP, Qiu SY, Xu D, Liang HX, Chen MX, Li X, Lin ZS, Liu WK, Zhou R. Epidemiology and clinical characteristics of human coronaviruses OC43, 229E, NL63, and HKU1: a study of hospitalized children with acute respiratory tract infection in Guangzhou, China. Eur J Clin Microbiol Infect Dis. 2018;37:363-9.

26. Lau SK, Woo PC, Yip CC, Tse H, Tsoi HW, Cheng VC, Lee P, Tang BS, Cheung $\mathrm{CH}$, Lee RA, et al. Coronavirus HKU1 and other coronavirus infections in Hong Kong. J Clin Microbiol. 2006;44:2063-71.

27. Gaunt E, Hardie A, Claas E, Simmonds P, Templeton K. Epidemiology and clinical presentations of the four human coronaviruses 229E, HKU1, NL63, and OC43 detected over 3 years using a novel multiplex real-time PCR method. J Clin Microbiol. 2010;48:2940-7.

\section{Ready to submit your research? Choose BMC and benefit from}

- fast, convenient online submission

- thorough peer review by experienced researchers in your field

- rapid publication on acceptance

- support for research data, including large and complex data types

- gold Open Access which fosters wider collaboration and increased citations

- maximum visibility for your research: over $100 \mathrm{M}$ website views per year

At BMC, research is always in progress.

Learn more biomedcentral.com/submissions 